\title{
PERFORMANCE OF FILTERS USED IN MODERN IRRIGATION NETWORK
}

\author{
El-Bukhari ${ }^{1}$ A.M.A., M.M. Hegazi ${ }^{2}$ and K.F.El-Bagoury ${ }^{2}$
}

\section{ABSTRACT}

Dual Irrigation Filter, as new integral filter, was developed, it has the ability to filter water regardless the particles specific gravity and without fear of screen clogging. The new filter is locally manufactured with combination between the sand separator and screen filter.

The dual irrigation filter was developed to have dual of application; as irrigation filters with a closed sedimentation tank, and as an alternative for the sedimentation pool with opened underflow to the atmosphere. With opened and closed underflow apex, the dual irrigation filter was tested to estimate and evaluate the filtration efficiency and outflow rate under different operation parameters. Three levels of feed suspension concentration (600, 1500 and 2400 ppm) prepared by using a coarse sandy loam soil sample, two levels of different operating pressure $(2.5$ and 4.0 psi) and three levels of the screen filtration degree (100, 150 and 200 mesh), were selected for the test.

With opened underflow apex, the highest mean of the filtration efficiency for the feed suspension of 600, 1500, 2400 ppm were 0.46205, 0.42126 and 0.38719 , respectively, for the different operating pressure of 4.0 and 2.5 psi were 0.46205 and 0.44135 , respectively, and for the screen filtration degree of 100, 150 and 200 mesh were 0.42855, 0.45515 and 0.46205 , respectively, whereas, with closed underflow apex, the highest value of the filtration efficiency for the feed suspension of 600, 1500, 2400 ppm were $0.4479,0.3985$ and 0.3601 , respectively, for the different operating pressure of 4.0 and 2.5 psi were 0.4479 and 0.4258 , respectively, and for the screen filtration degree of 100, 150 and 200 mesh were $0.4100,0.4367$ and 0.4479 respectively.

Key words: Sand separator, Screen filter, Dual irrigation filter, Filter performance.

\footnotetext{
${ }^{1}$ Ministry of Water and Irrigation, Amman, Jordan

${ }^{2}$ Agric. Eng. Dept., Fac. of Agric., Ain Shams Univ., Shoubra ElKheima, Cairo, Egypt
} 
The outflow rate was just statistically correlated to the different operating pressure; and in the case of opened apex, the highest mean of the outflow rate for the different operating pressure of 4.0 and 2.5 psi were 8.678 and $4.977 \mathrm{~m}^{3} / \mathrm{h}$, respectively, whereas, in the case of closed apex, they were 9.345 and $5.613 \mathrm{~m}^{3} / \mathrm{h}$, respectively.

\section{INTRODUCTION}

$\mathrm{O}$ ne of the main objectives for using modern irrigation networks is the management of the scarce water resources; which is the most common challenge facing by a large majority of farmers in developing countries. Egypt uses modern farm irrigation methods (sprinkler and trickle) on more than 27\% of its irrigated land (Mehmet and Bigak, 2002).

However, modern irrigation networks, such as sprinkler and trickle irrigation networks are limited by clogging, which is directly related to irrigation water quality and causes poor uniformity of application.

The type of filters to be used is closely related to the source of irrigation water, and in most field situations, it is very common to use a combination of more than one type of filters in the same irrigation network for proper water treatment. A general guide for different filter combinations for various levels of contamination and flow rates is shown in Table (1).

Table 1. Filter combinations for various levels of contamination and flow rates (Luke and Calder, 2005)

\begin{tabular}{|c|c|c|c|}
\hline \multicolumn{2}{|c|}{ Solids concentration* } & \multirow{2}{*}{ Flow rates $(\mathrm{L} / \mathrm{s})$} & \multirow{2}{*}{$\begin{array}{c}\text { Recommended } \\
\text { filters, in order of } \\
\text { placement } * *\end{array}$} \\
\hline Inorganic & Organic & & \\
\hline $\mathrm{L}$ & $\mathrm{L}$ & All & $\mathrm{A}$ \\
\hline $\mathrm{L}$ & $\mathrm{M}$ or $\mathrm{H}$ & up to 12 & $\mathrm{~B}+\mathrm{A}$ \\
\hline $\mathrm{L}$ & $\mathrm{M}$ or $\mathrm{H}$ & more than 12 & $\mathrm{~B}+\mathrm{D}+\mathrm{A}$ \\
\hline $\mathrm{M}$ or $\mathrm{H}$ & $\mathrm{L}$ & All & $\mathrm{C}+\mathrm{A}$ \\
\hline $\mathrm{M}$ or $\mathrm{H}$ & $\mathrm{M}$ or $\mathrm{H}$ & Less than 3 & $\mathrm{~B}+\mathrm{C}+\mathrm{A}$ \\
\hline $\mathrm{M}$ or $\mathrm{H}$ & $\mathrm{M}$ or $\mathrm{H}$ & 3 or more & $\mathrm{B}+\mathrm{C}+\mathrm{D}+\mathrm{A}$ \\
\hline
\end{tabular}


As shown in Table (1), whenever, the inorganic solids concentration is moderate (5 to $50 \mathrm{ppm}$ ) to high (more than $50 \mathrm{ppm}$ ), it is advisable to use hydrocyclone with a screen or disc filter, and one of these common combinations is the use of hydrocyclone just before screen filter to be as one system, in which vortical water flow separates heavier particles away from the fine mesh cartridge (Haman et al., 1989), but this type of filters is complex in its structure with large hydraulic loss and high cost (Xinzhong, 2006), in addition to the need for a large space which could be a critical problems at tight spaces.

Svarovsky (2000) illustrated that the usage of the hydrocyclone fall into several broad categories: clarification, thickening (or both simultaneously), classification, washing, sorting, liquid-liquid separation, liquid degassing and particle size measurement. The simplest way to operate a hydrocyclone is to open both the underflow and overflow to the atmosphere because this ensures correct hydraulic balance between the two outlets, however, in some applications it can operated with a closed grit pot (or sedimentation tank), likes the hydrocyclones used in filtering the irrigation water, and this can then be intermittently discharged by a manually or automatically operated purge valve.

Puprasert c. et al. (2002) studied the use of hydrocyclone as a pretreatment for run-off water and compared the performance of the two types of them, classical hydrocyclone and hydrocyclone equipped with Grit pot, they found that under the same conditions (feed concentration, types of solid and inlet pressure), the classical hydrocyclone showed efficiencies as high as $70 \%$ in terms of solid separation efficiency, and has the cutting diameter as low as $24 \mu \mathrm{m}$. But, the hydrocyclone equipped with Grit pot has nearly the solid separation efficiency at $65 \%$ and also has a cutting diameter as low as $24 \mu \mathrm{m}$. The study recommended that hydrocyclone equipped with Grit pot can replace a classical hydrocyclone in water treatment process because the total efficiency decreased by only $5-15 \%$.

Denis and Srivastava (2009) conducted a study to determine the removal efficiency and back wash frequency of sand filter, hydrocyclone filter, screen filter and their combinations, in addition to the emitter emission flow variation resulting from the usage of these filters. The 
study revealed that, to filter pond water; screen filter is recommended as a filtering media with a removal efficiency of $95.7 \%$ and emitter flow variation of 17.68, whereas, in the case of sewage water it is recommended that a combination of hydrocyclone and screen filter should be used at an influent concentration of $1950 \mathrm{ppm}$, with which, it was found that the emission flow variation was only $18.39 \%$, filtration removal efficiency was $97.5 \%$ and backwash frequency was 75 minutes. Xin-zhong (2006) designed and introduced an integral filter consist of a cylindrical body with tangential opening for feeding with the unfiltered irrigation water, and a conical screen that occupies the hollow center of the body which is connected to the outlet of the filtered irrigation water Figure (1).

He examined the new filter and compared it with an ordinary combination for the centrifugal and screen filter as one unit Figure (1), the results showed that the new filter could be used with the flow rate ranges from 80 to $140 \mathrm{~m}^{3} / \mathrm{h}$, and the hydraulic loss and the cost of the new filter is only about $32.5 \%$ to $68.6 \%$ and about $30 \%$ to $40 \%$, respectively, of the ordinary combination system.

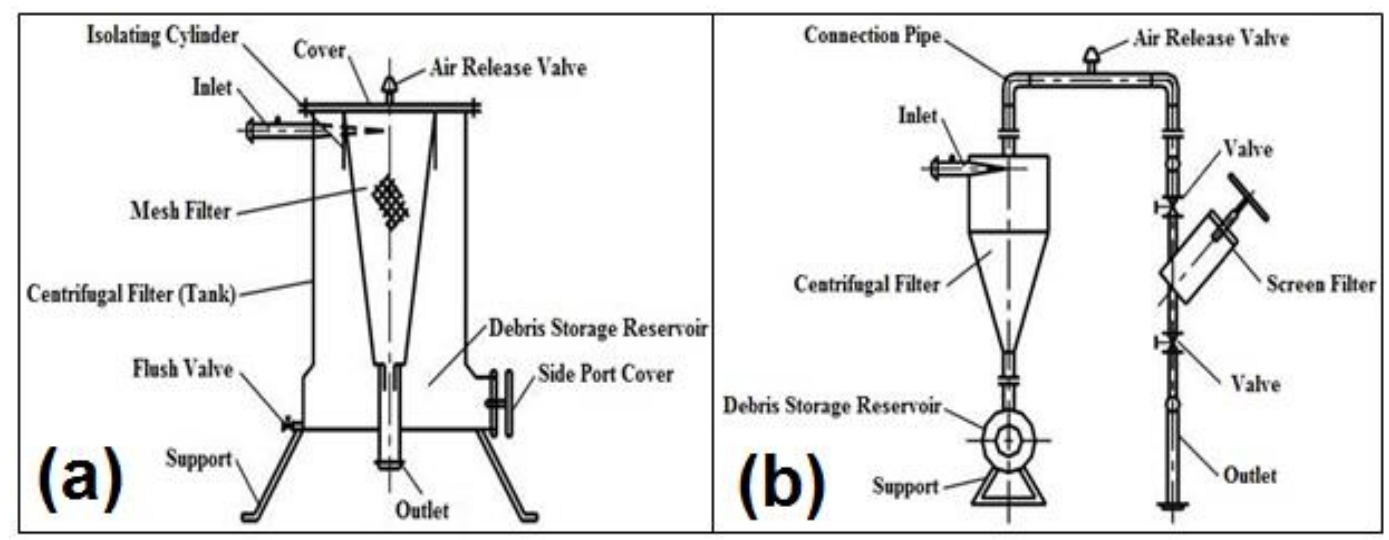

Fig.1. a: integral centrifugal screen filter, b: ordinary combination of centrifugal and screen filter (Xin-zhong, 2006)

Vieira et al., (2005) studied a filtering hydrocyclone whose conical section was replaced by a conical filtering wall Figure (2), to compare the performances of filtering hydrocyclones of two different designs, Bradley's and Rietema's 
At the same pressure drop and underflow diameter; Rietema's filtering hydrocyclones had a lower volumetric feed flow rate than the conventional device (without a filtering cone) and Bradley's filtering hydrocyclones showed an increase in this same variable.

In both designs, overall efficiency was influenced by the underflow-tothroughput ratio (ratio of the underflow volumetric flow rate to the feed volumetric flow rate), the overall efficiency of Rietema's filtering hydrocyclones increased more than that of the conventional device due to the increase in the values of the underflow-to-throughput ratio, which were responsible for the higher drag of solids by the underflow stream. For Bradley's filtering hydrocyclones, the opposite occurred because the reduction in the underflow-to-throughput ratio caused lower overall efficiencies than that of the conventional hydrocyclone.

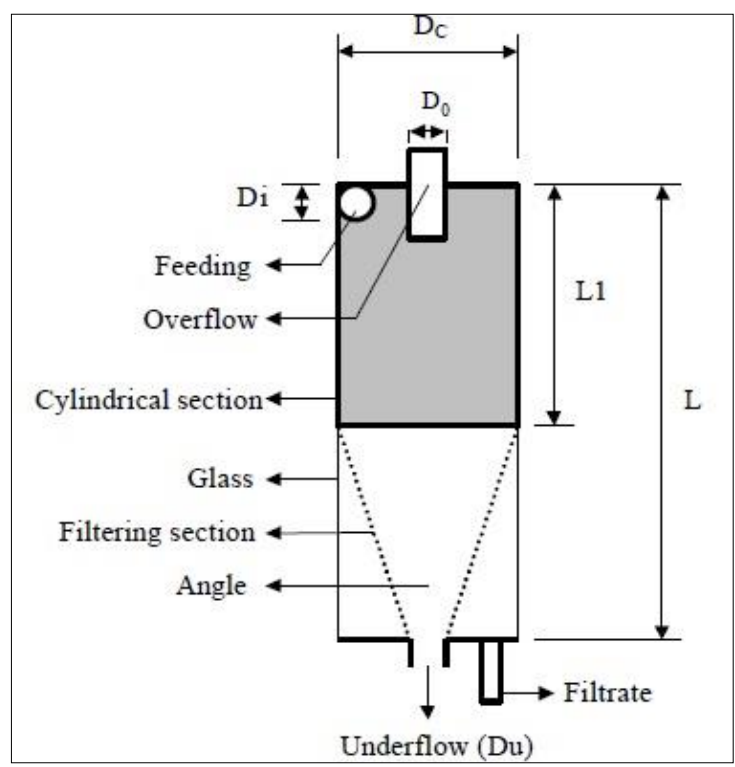

Fig.2. Filtering hydrocyclone (Vieira et al, 2005)

El-Bagoury (1998) developed a new cylindrical screen filter consisting of six perforated concave plates, covered with 60 - 100 mesh screen and they are arranged to allow water through the mesh to the secondary filtration through a spinal pipe.

It was found that increasing size of suspended particles from 125 to 375 $\mu \mathrm{m}$ lead to the increase in filtration efficiency from 90 to $97 \%, 80$ to $94 \%$ and 70 to $90 \%$ at concentration of contamination 10, 250, and $750 \mathrm{ppm}$, 
respectively. The optimum duration between back washings was 3.0 hours based on head drop of $5 \mathrm{~m}$ with $15 \mathrm{ppm}$ of contamination at discharge rate of $9.5 \mathrm{~m}^{3} / \mathrm{h}$ for river water. The duration can be increased to 10 hours daily by decreasing the filter inlet discharge rate to $3.5 \mathrm{~m}^{3} / \mathrm{h}$.

\section{Materials:}

\section{MATERIALS AND METHODS}

All apparatus and experiment were carried out in the Agriculture Engineering Department, Faculty of Agriculture, Ain Shams University. Shoubra El-Kheima, Qalyubia Governorate.

\section{The Dual Filter:}

From the points of filter performance enhancement, energy saving, cost effectiveness, low maintenance requirements and space saving, researcher designs and develops a new integral filter, given the name of "Dual Irrigation Filter" Figure (3), which is manufactured from economical local materials and combines between two types of irrigation filters; the hydrocyclone and screen filter in one unit.

The new developed filter is locally manufactured using steel sheet of 2 $\mathrm{mm}$ thickness. The filter consists of three main parts; the sand separator (hydrocyclone), screen filter and the sedimentation tank.

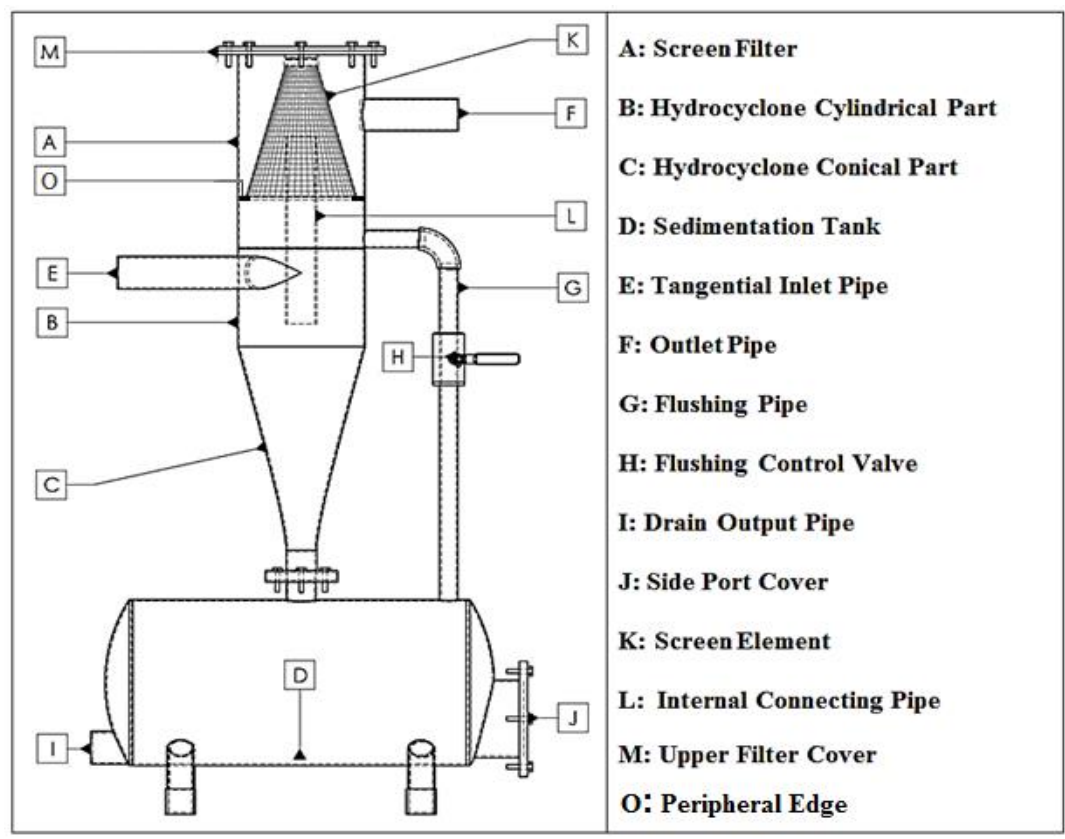

Fig.3. The Dual Filter 


\section{The Dual Filter components: \\ Sand separator:}

The sand separator consist of a conical part, attached to a cylindrical (20.32 cm of inner diameter) with a tangential opening (5.08 $\mathrm{cm}$ of inner diameter) for the feeding suspension, at the lower end there is an orifice (2.54 $\mathrm{cm}$ of inner diameter) attached to the conical part, known as apex, where the concentrated substance (Underflow) leaves to the sedimentation tank, whereas, the upper end has a pipe $(5.08 \mathrm{~cm}$ of inner diameter) with open sides mediated the cylindrical part known as Vortex Finder, where the diluted substance (Overflow) leaves to the screen filter.

\section{Screen filter:}

Screen filter (20.32 cm of inner diameter), which is attached to the outlet pipe (5.08 $\mathrm{cm}$ of inner diameter), consists of a removable conical screen element placed on a peripheral edge to form a cavity where the retained particles accumulate and then they are flushed away through a side orifice ( $2.54 \mathrm{~cm}$ of inner diameter) located at the bottom of this cavity and connected to the flushing pipe.

\section{Sedimentation tank:}

Sedimentation tank receives the concentrated substances discharged from the sand separator apex during the operation period, in addition to the accumulated particles at the screen filter cavity during the flushing process. It is connected to the apex through a flange in order to separate it, in such a way that, when the Dual Filter operated with the present of the underflow from the apex, it also gives capability for replacing the exchangeable conical bottom when it is needed. It has a drain outlet (5.08 $\mathrm{cm}$ of inner diameter) and side port opening (12.7 $\mathrm{cm}$ of inner diameter) used to get rid of sediments accumulated inside it.

\section{Screen elements:}

It is a conical shaped Figure (4), with $0.08939 \mathrm{~m}^{2}$ surface area, three filtration degree 100, 150 and 200 mesh were used, with an opening size of 140, 100 and 75 micron and effective open area of 32.3, 31.9 and $33.6 \%$, respectively. 


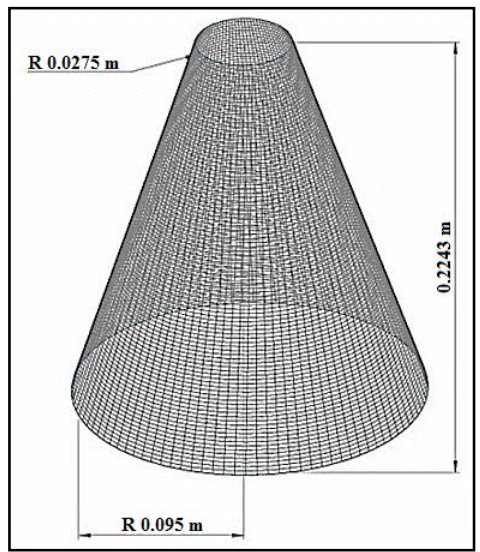

Fig.4. The conical screen element

\section{Feed suspension (impurities):}

Feed suspension in this test was prepared from tap water and a chosen soil sample with some physical analysis shown in Table (2). Three concentrations, 600, 1500 and 2400 ppm were applied by dissolving 240, 600 and $960 \mathrm{~g}$ of the soil sample in $400 \mathrm{~L}$ of water inside $1 \mathrm{~m}^{3}$ tank.

\section{Table 2. Soil sample mechanical analysis}

\begin{tabular}{|c|c|c|c|c|}
\hline Texture class & \multicolumn{4}{|c|}{ Particle size distribution (\%) } \\
\hline $\begin{array}{c}\text { Coarse Sandy } \\
\text { Loam }\end{array}$ & $\begin{array}{c}\text { Clay } \\
(<0.002 \mathrm{~mm})\end{array}$ & $\begin{array}{c}\text { Silt } \\
(0.002- \\
0.05 \mathrm{~mm})\end{array}$ & $\begin{array}{c}\text { Fine sand } \\
(0.05- \\
0.5 \mathrm{~mm}) \\
\end{array}$ & $\begin{array}{c}\text { Coarse } \\
\text { sand } \\
(0.5-1.0 \mathrm{~mm}) \\
\end{array}$ \\
\hline & 6.7 & 38.6 & 21.1 & 33.6 \\
\hline
\end{tabular}

\section{The mechanism of Dual Filter operation:}

The suspension is moved under pressure through the tangential entry, which imparts a swirling motion and thus generates a centrifugal force, solid-phase particles under the action of centrifugal forces are thrown to the apparatus wall, based on particle size and relative density; the higher mass particles remain in a downward spiral path along the walls of the conical section and gradually exit through the apex orifice, whereas, smaller mass particles migrate toward the center and spiral upward and out through the vortex finder. As water flows up through the connecting pipe into the screen filter cavity, it deflects off the surface of the filter 
screen element and particles are forced back down, away from the screen, into cavity to settle on the bottom.

\section{The mechanism of dual filter flushing:}

During the filter flushing operation, the following inlets/outlets should be opened (according to the signs used in figure 3); E, H and I, whereas, F an $\mathbf{J}$ should be closed, and when the suspension is moved under pressure through the tangential entry, the concentrated substances will exit through the apex, as usual as the operation mechanism, but the diluted substances, when they enter the screen filter cavity, will be enforced to exit through the bottom side orifice to the sedimentation tank by the flushing pipe carrying with them those particles which retained by the screen elements and accumulated at the cavity bottom, after then, both sources of contaminated water, which entered into sedimentation tank, will leave through the drain outlet carrying with them those sediments previously accumulated inside it.

\section{The test:}

The experimental test rig shown in Figure (5), consist of a $1 \mathrm{~m}^{3}$ tank that was equipped with a main head source centrifugal pump of the following specification:

- Discharge (Min. - Max.): $2-12 \mathrm{~m}^{3} / \mathrm{h}$.

- Head (Min. - Max.): $40-57$ m.

- Inlet/Outlet Diameter: 1.5/1".

Additional 1/5 hp centrifugal pump was used in order to maintain the entire solid in suspension during the cycle; the outlet discharge was measured by 2 " volumetric water meter installed at the outlet pipe, whereas, the different operating pressures across the dual filter were measured by using a pressure gauge installed on the inlet and outlet pipe. A number of volumetric control valves were used at different sites in order to have the desired pressure and discharge in addition to sampling process.

The Dual Filter used with this test rig was slightly modified from the original design by removing the sedimentation tank and using a volumetric control valve at the apex end in order to compare the filter performance with opened and closed apex. 


\section{Experimental test rig operation:}

The soil-water suspension used was prepared by filling the storage tank with 400 liter of tap water and dissolving the needed weight of the soil to obtain the desired concentration (240, 600 and $960 \mathrm{~g}$ to obtain 600,1500 and $2400 \mathrm{ppm}$, respectively). The entire solid was maintained in suspension during the operation period by using the $1 \mathrm{hp}$ centrifugal pump. The different operating pressure can be read at a pressure gauges installed on the inlet and outlet pipes and can be adjusted by two control volumetric valves, a major control valve (valve marked with $J$ in the figure 5) for rough adjustment and a minor control valve (valve marked with $I$ in the figure 5) for fine adjustment. The flow discharge from the Dual Filter can be obtained directly from the volumetric water-meter, by releasing the upper cover of the Dual Filter (marked with $\mathrm{M}$ in figure 3). The screen filter element can be changed to obtain the desired filtration degree.

At first, experiments with opened apex were performed to obtain the results in the presence of the underflow, which represents the using of the Dual Filter with the rainfall runoff, after that, the apex was closed and the experiments were performed in order to represent the filter operation as irrigation water filter. In both cases, all other valves were opened except valve I and valve $\mathrm{L}$ in (figure 5) which were closed during the operation period.

In the experiments with opened apex, the underflow and outflow were directly circulated into the storage tank, whereas, in experiments with closed apex, the underflow valve (valve marked with $M$ in the figure 5) was closed throughout the experiment, and the outflow directed to discharge outside the storage tank to allow filtered water to exit.

\section{Sampling:}

In experiments with opened apex, each case was run for 5 hours, and at the end of each hour two types of samples were taken, the feed samples and the outflow samples. The feed samples were taken from the line of the fine adjustment control valve (valve marked with $I$ in the figure 5) before circulating back into the storage tank. The outflow samples were taken from the outflow line (line after the volumetric water meter). 


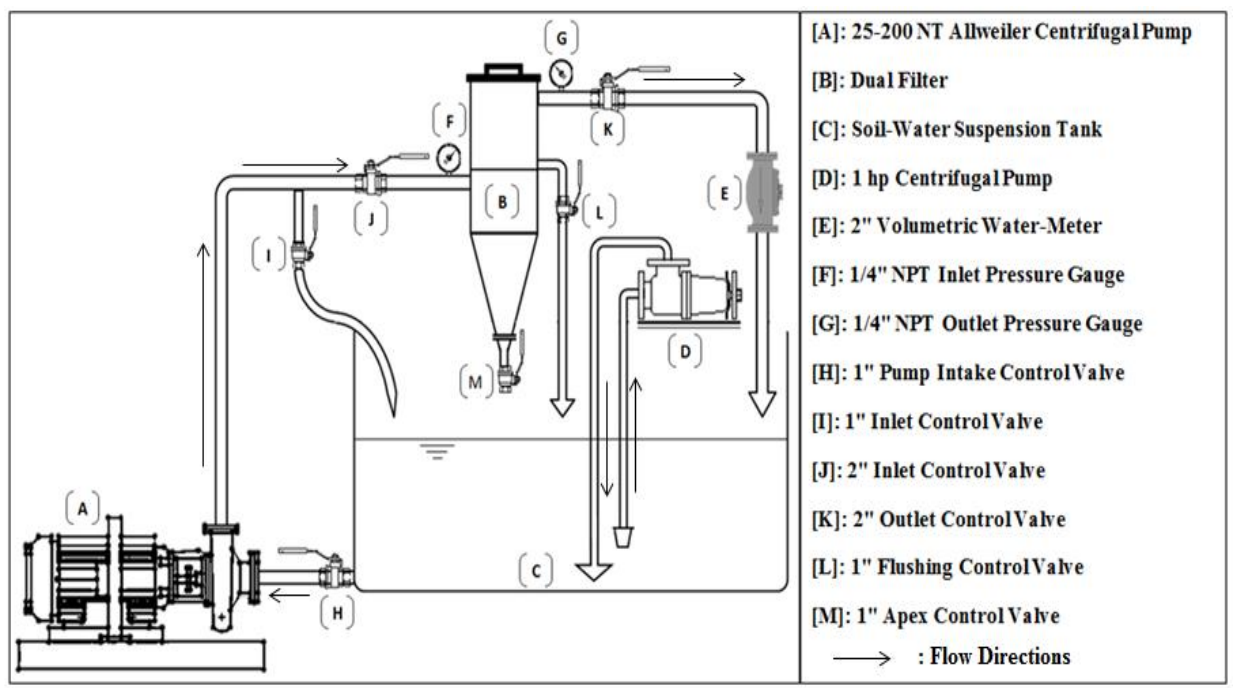

Fig.5. Sketch drawing for the experimental test rig

While in experiments with closed apex, and due to the limited volume of the soil-water suspension (400 L) and high filter outflow rate without recirculating it to the storage tank; each case was run for just 2 minutes, and during this period a cumulated sample were taken every 10 seconds from two sites, the first one was from the flushing line extended from the screen filter (line after the valve $\mathrm{L}$ in figure 5) to measure the particles weight retained by the screen element, and the second one was from the apex (valve $M$ in figure 5) to measure the particles weight which separated by the centrifugal action in the sand separator, and during the last 10 seconds a similar samples to those of the experiments with opened apex were taken (feed and outflow samples).

\section{Methods:}

The filtration efficiency was studied and compared under two cases; when the apex of the dual filter was opened and when it was closed, in both cases, all the materials and studying factors being meant were the same.

The different factors which were studied in this research can be categorized into three types; soil-water suspension concentration (with three levels of 600, 1500 and $2400 \mathrm{ppm}$ ), different operating pressures (with two levels of 2.5 and 4 psi) and filtration degree (with three levels 
of 100,150 and 200 mesh), this resulting with a total of 36 cases of study.

\section{Total Suspended solid (TSS) measurement method:}

TSS analysis was conducted using Standard Method 2540-D (APHA, 1995) for the collected samples from the feed and outflow points in the experiments with opened apex and closed apex. They were filtered by using a pre-weighed qualitative $15-\mathrm{cm}$ filter paper (Double Ring no. 102), they were then dried at $105{ }^{\circ} \mathrm{C}$ for 24 hours, after which they were cooled and weighed, and the total suspended solid weight obtained by subtracting the filter paper weight.

The samples collected from the apex and flushing line in the experiments with closed apex were manipulated according to the Standard Methods 2540-B (APHA, 1995), they were placed in pre-weighed aluminum trays and evaporated to dryness at $98{ }^{0} \mathrm{C}\left(2^{\circ} \mathrm{C}\right.$ below boiling to prevent splattering), they were then dried at $105{ }^{\circ} \mathrm{C}$ for 24 hours, after which they were cooled and weighed, and the total suspended solid weight obtained by subtracting the aluminum trays weight.

\section{Method to determine the Dual Filter efficiency:}

Svarovsky (2000) defined the total (or overall) efficiency ET as simply the ratio of the mass of all particles separated to the mass of all solids fed into the separator, therefore, in the experiments with opened apex, the total efficiency ET could be defined as:

$$
\mathbf{E T}=\left(\mathbf{M}_{\mathrm{c}} / \mathrm{M}\right) * \mathbf{1 0 0}
$$

Where:

M: The mass flow rate of the feed (in $\mathrm{kg} \mathrm{s}^{-1}$ ).

$\mathrm{M}_{\mathrm{c}}$ : The mass flow rate of the concentrated underflow (in $\mathrm{kg} \mathrm{s}^{-1}$ ).

As some liquid accompanying the solids in the underflow (dead flux), a certain amount of fine solids is removed with the concentrated underflow, resulting in increasing the efficiency than the actual value. 
The Reduced Efficiency is a definition of efficiency introduced to subtract the contribution of the dead flux, the best and most widely used formula is one due to Kelsall (1966):

$$
\mathbf{E T}^{\prime}=\left(\left(\mathbf{E T}-\mathbf{R}_{\mathbf{f}}\right) /\left(\mathbf{1}-\mathbf{R}_{\mathbf{f}}\right)\right)^{* 100}
$$

Where:

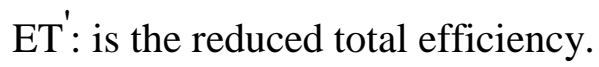

ET: is the total efficiency as defined by equation 2.1.

$\mathrm{R}_{\mathrm{f}}$ : is the underflow-to-feed ratsio (by volume).

Svarovsky (2000) indicate that ET" could be calculated according to the mass concentration of the solid in the feed and outflow as:

$$
\mathrm{ET}^{\prime}=\left(\left(\mathrm{C}-\mathrm{C}_{\mathbf{0}}\right) / \mathrm{C}\right) * 100
$$

Where:

$\mathrm{C}$ : is the mass concentration of solids in the feed (in $\mathrm{g} \mathrm{L}^{-1}$ ).

$\mathrm{C}_{\mathrm{O}}$ is the mass concentration of solids in the outflow (in $\mathrm{g} \mathrm{L}^{-1}$ ).

For the experiments with closed apex, the outflow rate is equal to the feed rate, and the ET' doesn't differ from ET, consequently, equation (2.3) is also applicable. On other hand, the ET could be found by relating the total weight of the collected particles at apex point, which thrown by hydrocyclone, and particles retained by screen element, to the total amount of suspended solid entered the filter during the operation period:

$\mathbf{E T}=\left(\left(\mathbf{W}_{\mathrm{a}}+\mathbf{W}_{\mathrm{s}}\right) /(\mathbf{C} * \mathbf{Q} * \mathbf{D})\right) * \mathbf{1 0 0}$

Where:

ET: is the total efficiency.

$\mathrm{W}_{\mathrm{a}}$ : is the total mass of solids collected from the apex Point $(\mathrm{g})$.

$\mathrm{W}_{\mathrm{s}}$ : is the total mass of solids retained by the screen element $(\mathrm{g})$.

$\mathrm{C}$ : is the mass concentration of solids in the feed (in $\mathrm{g} \mathrm{L}^{-1}$ ).

$\mathrm{Q}$ : is the feed rate $(\mathrm{L} / \mathrm{s})$.

$\mathrm{D}$ : is the operation period (s). 


\section{Method to determine the Dual Filter outflow rate:}

The dual filter outflow rate was directly measured through the water meter installed at the outlet line in the test rig (marked with $\mathrm{E}$ in the figure 5)

\section{Data analysis method:}

The correlations between filtration efficiency and discharge with the independent factors (soil-water suspension concentration, different operating pressures and filtration degree) were determined by using SPSS software, SPSS Inc., (2005).

\section{RESULTS AND DISCUSSION}

\section{Filtration Efficiency:}

The presented results in Table (3), showing that the highest and lowest mean values for the filtration efficiency in the experiment of opened apex was $(0.46205)$ and $(0.32111)$, respectively, whereas in the experiment of closed apex was (0.4479) and (0.2920) , respectively, and in both types of the experiments the highest value was obtained when the dual filter operated at different operating pressure of $4.0 \mathrm{psi}$, suspension concentration of $600 \mathrm{ppm}$ and filtration degree of $200 \mathrm{mesh}$, whereas, the lowest value was obtained when the dual filter operated at different operating pressure of $2.5 \mathrm{psi}$, suspension concentration of $2400 \mathrm{ppm}$ and filtration degree of 100 mesh.

\section{The Outflow Rate:}

The results are presented in Table (3), shows that the highest and lowest mean values for the outflow rate in the experiment of opened apex was (8.678) and (4.351) $\mathrm{m}^{3} / \mathrm{h}$, respectively, whereas in the in the experiment of closed apex was $(9.345)$ and $(4.501) \mathrm{m}^{3} / \mathrm{h}$, respectively, and in both types of experiments the highest value was obtained when the Dual Filter operated at different operating pressure of 4.0 psi, whereas, the lowest value was obtained when the Dual Filter operated at different operating pressure of 2.5 psi.

\section{Correlation between Subjects and Independent Factors:}

Table (4) shows that filtration efficiency is negatively correlated to the suspension concentration, and it is positively correlated to the different operating pressure and filtration degree. While discharge is positively 
correlated to the different operating pressure and doesn't show any correlation to the suspension concentration or filtration degree.

Table 3. The filtration efficiency and the outflow rate of the Dual

Filter

\begin{tabular}{ccccccc}
\hline \multicolumn{2}{c}{ Operation Parameter } & \multicolumn{2}{c}{ With Closed Apex } & With Opened Apex \\
\hline $\begin{array}{c}\text { Suspension } \\
\text { Concentrat } \\
\text { ion (ppm) }\end{array}$ & $\begin{array}{c}\text { Different } \\
\text { Operating } \\
\text { Pressure } \\
\text { (psi) }\end{array}$ & $\begin{array}{c}\text { Filtration } \\
\text { Degree } \\
\text { (mesh) }\end{array}$ & $\begin{array}{c}\text { Filtration } \\
\text { Efficiency }\end{array}$ & $\begin{array}{c}\text { Outflow } \\
\text { Rate } \mathbf{m}^{\mathbf{3}} / \mathbf{h}\end{array}$ & $\begin{array}{c}\text { Filtration } \\
\text { Efficiency }\end{array}$ & $\begin{array}{c}\text { Outflow } \\
\text { Rate } \mathbf{~ m}^{\mathbf{3}} \mathbf{h}\end{array}$ \\
\hline 600 & 4.0 & 100 & 0.4100 & 8.949 & 0.42855 & 8.544 \\
600 & 2.5 & 100 & 0.3780 & 5.394 & 0.39795 & 4.646 \\
1500 & 4.0 & 100 & 0.3790 & 9.267 & 0.40488 & 8.675 \\
1500 & 2.5 & 100 & 0.3350 & 5.588 & 0.36359 & 4.873 \\
2400 & 4.0 & 100 & 0.3330 & 9.345 & 0.36397 & 8.557 \\
2400 & 2.5 & 100 & 0.2920 & 5.613 & 0.32111 & 4.923 \\
\hline 600 & 4.0 & 150 & 0.4367 & 8.898 & 0.45515 & 8.531 \\
600 & 2.5 & 150 & 0.4060 & 4.501 & 0.42060 & 4.351 \\
1500 & 4.0 & 150 & 0.3920 & 9.206 & 0.41587 & 8.678 \\
1500 & 2.5 & 150 & 0.3470 & 4.873 & 0.37058 & 4.562 \\
2400 & 4.0 & 150 & 0.3520 & 9.084 & 0.37692 & 8.472 \\
2400 & 2.5 & 150 & 0.3130 & 5.325 & 0.33874 & 4.926 \\
\hline 600 & 4.0 & 200 & 0.4479 & 8.791 & 0.46205 & 8.507 \\
600 & 2.5 & 200 & 0.4258 & 5.158 & 0.44135 & 4.970 \\
1500 & 4.0 & 200 & 0.3985 & 9.136 & 0.42126 & 8.642 \\
1500 & 2.5 & 200 & 0.3670 & 5.327 & 0.39281 & 4.977 \\
2400 & 4.0 & 200 & 0.3601 & 9.232 & 0.38719 & 8.583 \\
2400 & 2.5 & 200 & 0.3328 & 5.307 & 0.36047 & 4.899 \\
\hline
\end{tabular}

Table 4. Subjects-Factors correlation

\begin{tabular}{|c|c|c|c|c|c|c|c|c|c|}
\hline \multirow[b]{2}{*}{$\begin{array}{l}\text { Subjects } \\
\text { Under the } \\
\text { Study }\end{array}$} & \multicolumn{3}{|c|}{$\begin{array}{c}\text { Suspension } \\
\text { Concentration }\end{array}$} & \multicolumn{3}{|c|}{$\begin{array}{c}\text { Different Operating } \\
\text { Pressures } \\
\end{array}$} & \multicolumn{3}{|c|}{ Filtration Degree } \\
\hline & ن & 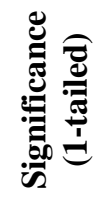 & 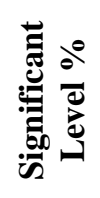 & ن & 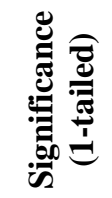 & 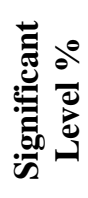 & 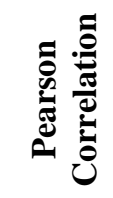 & 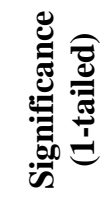 & 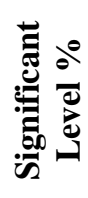 \\
\hline Filtration Eff. & -0.804 & 0.000 & 1 & 0.443 & 0.000 & 1 & 0.327 & 0.008 & 1 \\
\hline Discharge & 0.029 & 0.454 & - & 0.997 & 0.000 & 1 & 0.013 & 0.480 & - \\
\hline
\end{tabular}




\section{Comparison between Experiments with Opened Apex and with}

\section{Closed Apex:}

Reference to the Table (3), the comparison could be summarized into Table (5). These results show that, under the same conditions (Suspension concentration, different operating pressure and filtration degree), the filtration efficiency with closed apex was lower than that with opened apex by approximately $3-9 \%$, which was not a large difference, and agree with the results obtained by (Puprasert c. et al., 2002), whereas, the outflow rate with closed apex was higher than with opened apex by approximately $3-14 \%$.

Table 5. Filtration efficiency and outflow rate comparison

\begin{tabular}{|c|c|c|c|c|}
\hline $\begin{array}{c}\text { Suspension } \\
\text { Concentrati } \\
\text { on }(\mathbf{p p m})\end{array}$ & $\begin{array}{l}\text { Different } \\
\text { Pressure } \\
\quad(\text { psi })\end{array}$ & $\begin{array}{c}\text { Filtration } \\
\text { Degree } \\
\text { (mesh) }\end{array}$ & $\begin{array}{c}\text { Difference } \\
\text { in Filtration } \\
\text { Eff. }(\%)\end{array}$ & $\begin{array}{c}\text { Difference } \\
\text { in Outflow } \\
\text { Rate }(\%)\end{array}$ \\
\hline 600 & 4 & 100 & 4.33 & 4.53 \\
\hline 600 & 2.5 & 100 & 5.01 & 13.87 \\
\hline 1500 & 4 & 100 & 6.39 & 6.39 \\
\hline 1500 & 2.5 & 100 & 7.86 & 12.80 \\
\hline 2400 & 4 & 100 & 8.51 & 8.43 \\
\hline 2400 & 2.5 & 100 & 9.07 & 12.29 \\
\hline 600 & 4 & 150 & 4.05 & 4.12 \\
\hline 600 & 2.5 & 150 & 3.47 & 3.33 \\
\hline 1500 & 4 & 150 & 5.74 & 5.74 \\
\hline 1500 & 2.5 & 150 & 6.36 & 6.38 \\
\hline 2400 & 4 & 150 & 6.61 & 6.74 \\
\hline 2400 & 2.5 & 150 & 7.60 & 7.49 \\
\hline 600 & 4 & 200 & 3.06 & 3.23 \\
\hline 600 & 2.5 & 200 & 3.52 & 3.64 \\
\hline 1500 & 4 & 200 & 5.40 & 5.41 \\
\hline 1500 & 2.5 & 200 & 6.57 & 6.57 \\
\hline 2400 & 4 & 200 & 7.00 & 7.03 \\
\hline 2400 & 2.5 & 200 & 7.68 & 7.69 \\
\hline
\end{tabular}




\section{CONCLUSION}

The filtration efficiency and outflow rate for the new developed integral filter was tested and evaluated under different operation parameters in two cases; with opened underflow apex and with closed underflow apex.

The results showed that the dual filter had a high filtration efficiency (in relative to the $54.7 \%$ of sand portion in the soil sample used to prepare the feed suspension), where the highest mean value was $(0.46205)$ and (0.4479), and the lowest mean value was (0.32111) and (0.2920) for the case of opened and closed underflow, respectively. Whereas, the highest mean value for the outflow rate was (8.68) and $(9.35) \mathrm{m}^{3} / \mathrm{h}$, and the lowest mean value was (4.35) and (4.5) $\mathrm{m}^{3} / \mathrm{h}$ for the case of opened and closed underflow, respectively.

Statistically, the filtration efficiency was significantly correlated to all of the different operation parameters, whereas, the outflow rate was just significantly correlated to the different operating pressure. With closed underflow apex, the filtration efficiency was lower than that with opened underflow apex by approximately $3-9 \%$, and the outflow rate was higher by approximately $3-14 \%$.

These results reveal that:

- The dual filter has a high performance, in relative to the fine $(0.05$ - $0.5 \mathrm{~mm})$ and coarse $(0.5-0.1 \mathrm{~mm})$ sand portion in the soil sample used to prepare the feed suspension.

- Has a high performance, in relative to the high concentration of the feed suspension.

- Saves in the energy due to the low value of the different operating pressure.

- Saves in the effort and time due to the reduced maintenance needed for the filter assembly as well as the total system and for long period of operation.

Moreover, in terms of the filter design, the dual filter has a numbers of special features such as: 
- The ability to filter water regardless the particles specific gravity and with a very low potential of screen clogging.

- Reduction floor of the space requirements.

- No moving parts to replace or break down.

- Several mesh/micron options available.

- Locally manufactured in Egypt from economical local materials. Consequently, all of the mentioned features make the Dual Filter one of the competitive filters used in the modern irrigation network.

\section{REFERENCES}

APHA (1999), Standard Methods for the Examination of Water and Wastewater - Method 2540B, 2540D. American Public Health Association. American Water Works Association, Water Environment Federation, PP. 1 - 6.

Denis, D. and S.K. Srivastava (2009), Effect of Filter and Emitter Clogging on Emitter Flow Variation Under Variable Water Quality, International Agricultural Engineering Conference, Bangkok, Thailand. PP. 67 - 79.

El-Bagoury, K. F. (1998), Study on some trickle irrigation problems in Egypt. MS. Agri. Mech., Dep. Agri. Fac., Ain Shames Univ., Cairo, Egypt: 5-10.

Haman, D. Z., Allen G. Smajstrla and Fedro S. Zazueta (1989), Screen Filters in Trickle Irrigation Systems, AE-61. University of Florida, Gainesville, FL. PP. 1 - 5.

Kelsall, D. F. ( 1966), The theory and applications of the hydrocyclones. In: Solid/liquid separation; a review and bibliography. (Poole J.B. and D. Doyle Ed.), H.M.S.O., London. UK PP. 68 - 89.

Luke G. and T. Calder (2005), Blockages in irrigation lines, Farmnote 41/1990, Department of Agriculture and Food, Western Australia.

<http://www.agric.wa.gov.au/PC_92488.html $>$. 
Mehmet, O. and H. A. Bigak (2002), Modern and Traditional Irrigation Technologies in the Eastern Mediterranean, International Development Research Centre, P. 19.

Puprasert, C., Hebrard, G., Lopez, L. and Aurelle, Y. (2004), Potential of using Hydrocyclone and Hydrocyclone equipped with Grit pot as a pre-treatment in run-off water treatment, Chemical Engineering and Processing 43: 67-83.

SPSS Inc. (2005), SPSS for Windows. Release 14.0. SPSS, Inc., Chicago, Illinois, USA.

Svarovsky L. (2000), Solid-Liquid Separation, fourth Edition. Butterworth-Heinemann, Oxford, UK PP. 191 - 243.

Vieira, L. G. M., E. A. Barbosa, J.J. R. Damasceno and M. A. S. Barrozo (2005), Performance Analysis and Design of Filtering Hydrocyclones, Brazilian Journal of Chemical Engineering, 22 (1): 143 - 152.

Xin-zhong, S. (2006), Experiments on integral centrifugal screen panel and micro-irrigation filter, Drainage and Irrigation Machinery, 24 (3): 20 - 22.

$$
\begin{aligned}
& \text { الملخص العربوي } \\
& \text { اداء المرشحات المستخدمة في شبكات الري الحديث }
\end{aligned}
$$

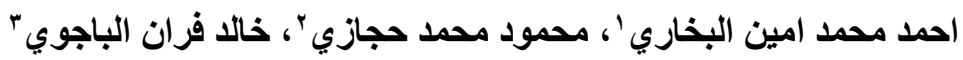

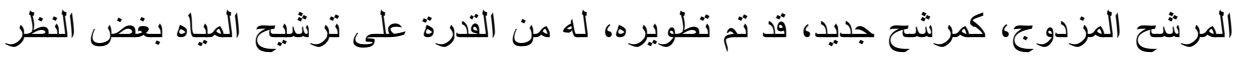

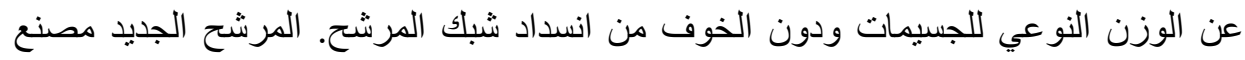

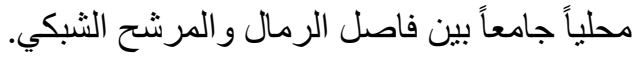

$$
\begin{aligned}
& \text { تم تطوير المرشح المزدوج ليكون له تطبيقا مزدوجا؛ كمرشح لمياه الري بوجود خزان ترسيبي، } \\
& \text { وكبديل لحوض الترسيب بتصرف سفلي مفتوح للغلاف الجوي. } \\
& \text { ' وزارة المياه والري، عمان - الأردن. } \\
& \text { r " قسم الهندسة الزراعية, كلية الزراعة، جامعه عيس شمس، شبرا الخيمة، القاهرة ـ مصر }
\end{aligned}
$$


بفتح واغلاق فتحة التصرف السفلي، تم اختبار المرشح المزدوج لتقدير وتقييم كفاءة الترشيح ومعدل التصريف تحت عو امل تشغيلية مختلفة. ثلاث مستويات من تركيز الثوائب في مصدر

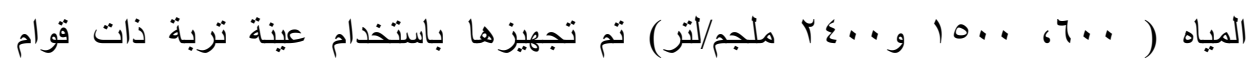

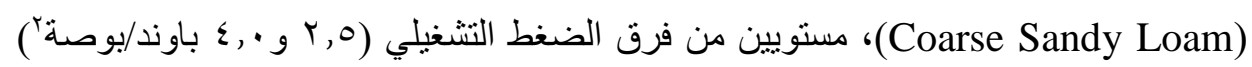

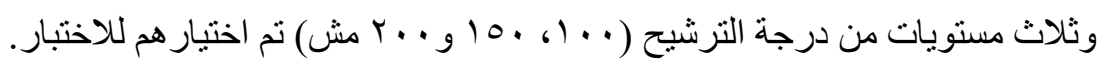

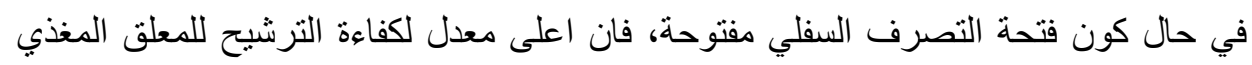

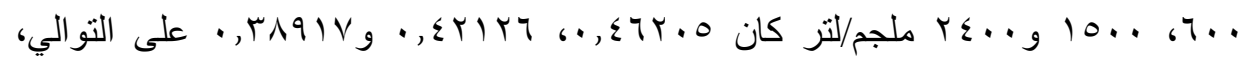

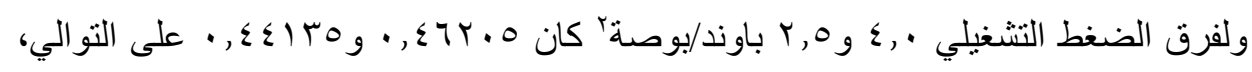

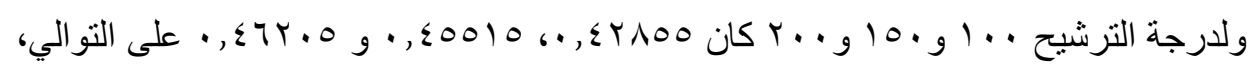

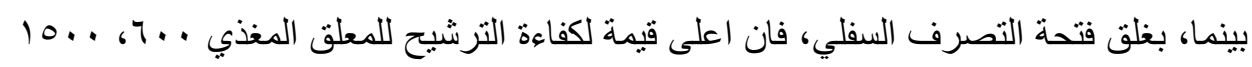

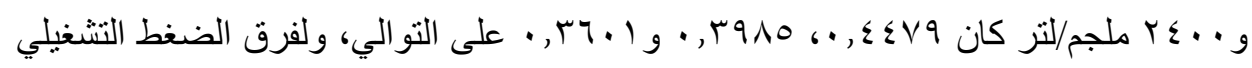

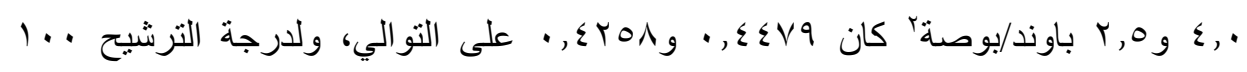

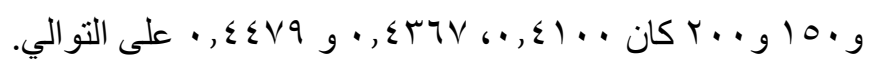

ارتبط معدل التصرف بشكل معنوي مع فرق الضغط التشغيلي فقط، وفي حال كون فتحة

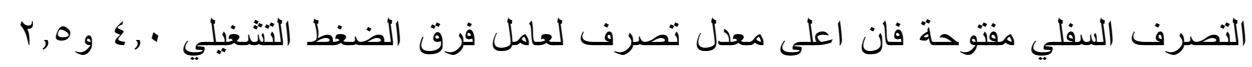

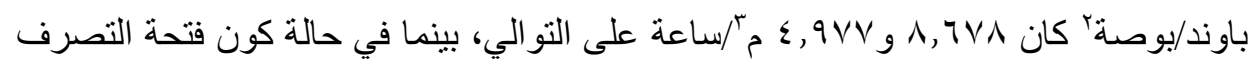

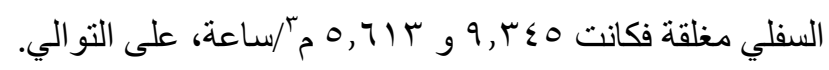

